\title{
Epitaxial Growth of Gallium Arsenide
}

\author{
Shinya IIda, Hitoshi Sato, Motohisa Hirao \\ and Yutaka TAKEDA \\ Hitachi Central Research Laboratory \\ Kokubunji, Tokyo
}

Received March 17, 1969

\begin{abstract}
The preparation of the epitaxial GaAs for the millimeter wave devices using an open flow system is described here. A high purity arsenic trichloride as a transport agent and doped GaAs single crystal as a source material were used in this work.

Epitaxial $n^{+}$on $n^{++}$junctions for the devices have been formed by deposition of the epitaxial layers $2 \sim 4 \mu$ in thickness, doped to $1 \sim 3 \times 10^{17} \mathrm{~cm}^{-3}$ onto $n$-type (100) substrates doped with Te or Se to $>3.5 \times 10^{18} \mathrm{~cm}^{-3}\left(<9 \times 10^{-4} \Omega \mathrm{cm}\right)$. The selection of the favorable epitaxial wafers for the devices was made by the bonding test method. Ranges of the growth parameters such as substrate temperature and hydrogen flow rate, selection of doping impurity and special substrate preparation were established by this method. Reproducible high quality epitaxial wafers with the abrupt junctions between the epitaxial layer and the substrate have been produced, and excellent millimeter wave devices such as mixer diodes have been fabricated in this work.
\end{abstract}

\section{Introduction}

Vapor phase epitaxial growth is an effective method for preparing various GaAs devices $^{1), 2)}$. Epitaxial deposition using $\mathrm{Ga}$ as a source is suitable for making a high purity layer $^{3}$ ). The deposition using doped or undoped $\mathrm{GaAs}$ as a source ${ }^{4)}$ is also useful because of the easy control of the impurity doping or of layer thickness.

To fabricate good millimeter wave devices, the epitaxial wafers should be satisfied following conditions,

1. Resistivity of substrate is below $10^{-3} \Omega \mathrm{cm}$.

2. Carrier concentration in the epitaxial layer is in range $1 \sim 3 \times 10^{17} \mathrm{~cm}^{-3}$.

3. Growth surface is shiny and tlat.

4. Impurity concentration profile in the layer is homogeneous and have abrupt interface.

It is very difficult to satisfy the above conditions in usual growth method. Further, it is also difficult by usual measurement such as carrier concentration to evaluate the suitableness in electrical properties of the wafers to the devices.

In this paper, noble epitaxial techniques and simple evaluation method of the epitaxial wafers for fabrication of the excellent millimeter wave devices ${ }^{5), 6)}$ are described.

\section{Experimental}

Epitaxial arrangements and a typical temperature profile are shown in Fig. 1. The reactor consists of a high purity quartz which has a diameter of about $10 \mathrm{~mm}$ at the inlet and $30 \mathrm{~mm}$ at the outlet. By making rapid flow, the small part of the reactor prevents arsenic deposition which is produced by reverse diffusion of arsenic vapor reduced from arsenic trichloride $\left(\mathrm{AsCl}_{3}\right)$. High purity $\mathrm{AsCl}_{3}$ (99.99999\%) and hydrogen (palladium diffused) were used. GaAs crystals used for source material were Te-, S- and Sn-doped to $1 \sim 3 \times 10^{17} \mathrm{~cm}^{-3}$.

$\mathrm{GaAs}$ single crystals used for substrates were 


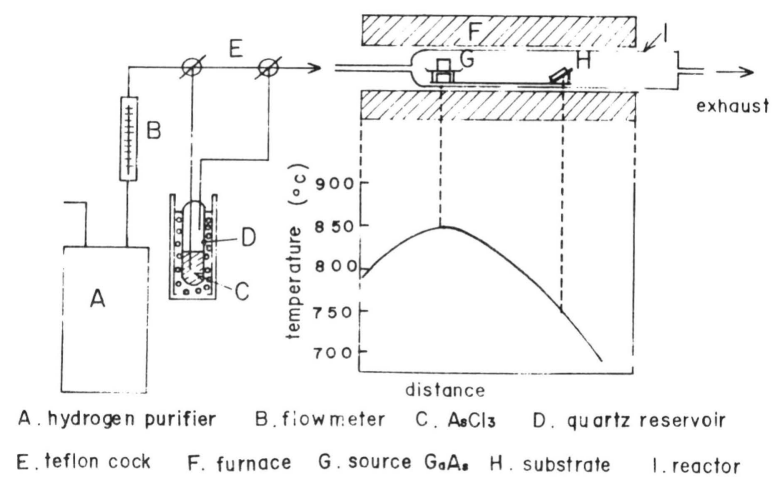

Fig. 1 Epitaxial arrangement and typical temperature profile

Te- or Se-doped to above $3.5 \times 10^{18} \mathrm{~cm}^{-3}$ and the resistivity was below $0.9 \times 10^{-3} \Omega \mathrm{cm}$. This specification was successfully completed with Te- and Se-doped crystals in melt growth and was also successfully completed in case of Sndoped epitaxially deposited crystals using $\mathrm{SnCl}_{4}$. Etching rates of source material were determined by weight loss.

The thickness of epitaxial layers was determined by the infrared interference method within about 10 percent accuracy. The profile of the carrier concentration in the layer was determined from the differential capacitance-voltage characteristics of Schottky diodes formed by evaporating gold onto the surface, and from the point contact breakdown (PCB) method using a calibration curve as shown in Fig. 2.

The evaluation of properties of epitaxial

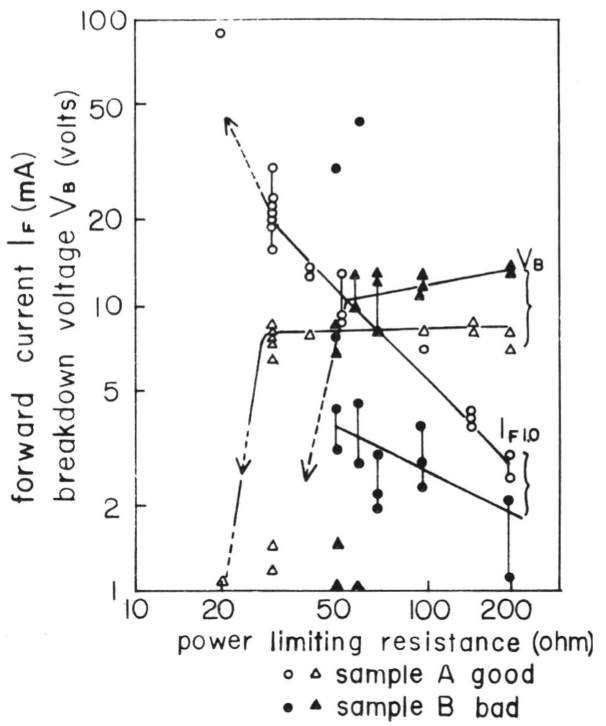

Fig. 3 Typical relationship of forward current, breakdown voltage vs. bonding power in the bonding tests

layers was carried out by bonding tests ${ }^{5), 6)}$ in the following manners. As in the same fabrication process of the bonded type diodes, epitaxial layer on the substrate was bonded with Au-Zn wire of $20 \mu \mathrm{m}$ in diameter, and many bonded diodes having various junction areas were made by controlling bonding power. By measuring the current-voltage characteristics of each diodes, the forward current at 1 volt $\left(\mathrm{I}_{\mathrm{F}}\right.$ 1.0 $)$ and breakdown voltage $\left(V_{B}\right)$ were obtained and the relation was plotted as a function of the bonding power. Fig. 3 shows the typical relationship $I_{F}$ 1.0, $V_{B}$ versus the bonding powers which are indicated as

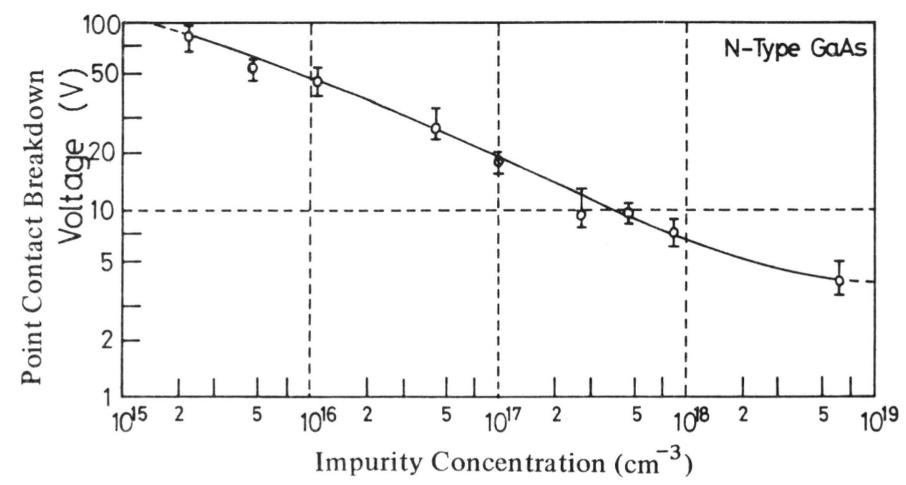

Fig. 2 Point contact breakdown voltage versus impurity concentration on $n$-type GaAs 
the values of the power limiting resistances at constant voltage source. From the values of the breakdown voltage and their dependence on junction area, from the forward current correspond to the point at which the breakdown voltage of the diodes suddenly lowers and from these scatterings data, it can be seen whether the epitaxial layers under estimated is suitable to the millimeter wave diodes or not.

Therefore,

a) The impurity concentration and profile across the layer is known because the PCB voltage and the breakdown voltage of bonded diodes were previously calibrated, respectively. b) The order of perfectness in the layer is estimated.

c) Electrical properties- related to surface quality are known because the bonding conditions and the characteristics of bonded diodes are strongly affected by the contamination of surface such as oxides.

Preparation of substrate before deposition was carefully taken. A mirror-like finished (100) wafer was chemically polished with an etchant composed of $5 \mathrm{H}_{2} \mathrm{SO}_{4}: 1 \mathrm{H}_{2} \mathrm{O}_{2}: 1 \mathrm{H}_{2} \mathrm{O}$ solution in $5 \sim 10$ min., and rinsed in de-ionized water, distilled water, and isopropanol. The substrate was dried in a cleanbench and was inserted in the reactor which had already been baked in purified hydrogen.

\section{Effects of Growth Parameters}

\subsection{Substrate Temperature}

Smooth surfaces were obtained at the substrate temperature of $750^{\circ} \sim 800^{\circ} \mathrm{C}$, but the surfaces became a slightly rough at $790^{\circ} \sim$ $800^{\circ} \mathrm{C}$ : In this case the source temperature was always kept $100^{\circ} \mathrm{C}$ higher than that of the substrate. At above $800^{\circ} \mathrm{C}$, many etch pits appeared on the surface and below $750^{\circ} \mathrm{C}$ humps appeared as the temperature decreased.

Growth rate versus reciprocal absolute substrate temperature curves are shown in Fig. 4. It can be seen from this figure that the slopes of the curves are dissimilar to different flow rate of hydrogen bubbled through the $\mathrm{AsCl}_{3}$ reservoir, and that the temperature at which pits appeared on the surface corresponds to that of falling off

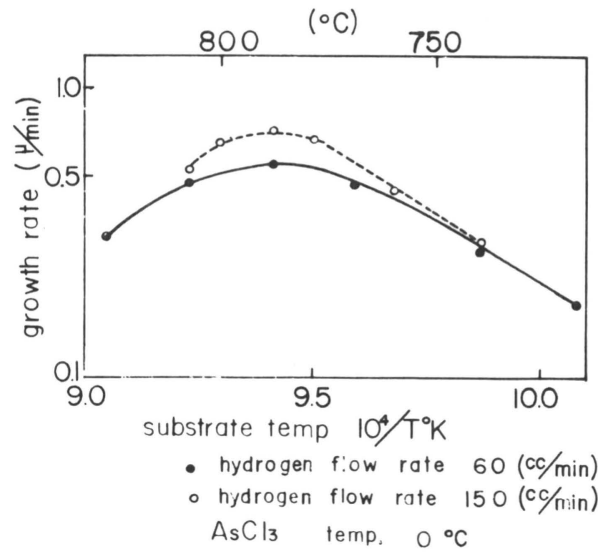

Fig. 4 Temperature dependence of growth rate of $\mathrm{GaAs}$ at constant hydrogen flow rate, $\mathrm{AsCl}_{3}$ temperature and temperature difference between source and substrate

of the growth rate obtained at higher growth temperatures.

As the growth rate is closely related to the etching rate of the source material, etching kinetics was also studied. The etching rate versus the source temperature curves are shown in Fig. 5. Slopes of the curves are similar in both different hydrogen flow rates. The activation energy was determined to be about $18 \mathrm{Kcal}$ /mole.

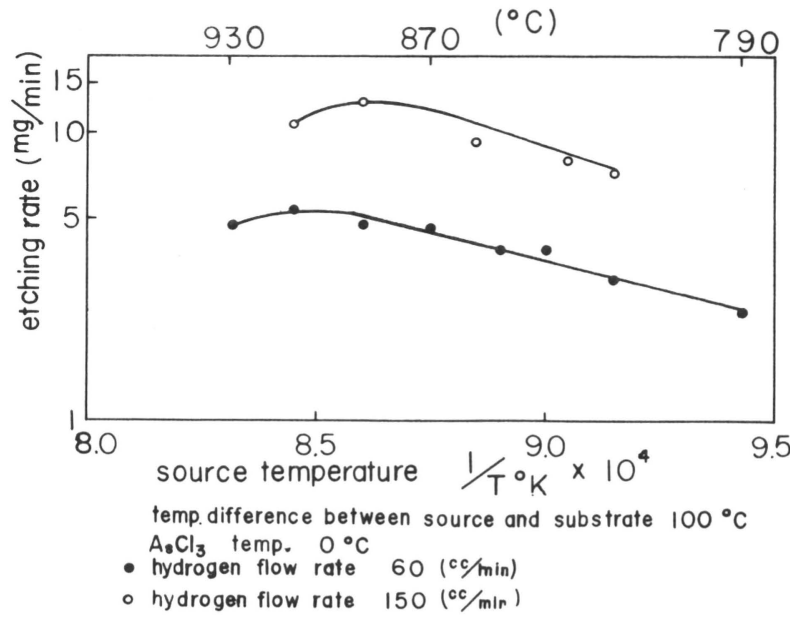

Fig. 5 Temperature dependence of etching rate of source material at constant flow rate and $\mathrm{AsCl}_{3}$ temperature 
Table 1 Representative data of the bonding tests for the epitaxial layers grown at different substrate temperatures

\begin{tabular}{l|c|c|cc|c|c}
\hline $\begin{array}{c}\text { Sample } \\
\text { No. }\end{array}$ & $\begin{array}{c}\text { Subst. } \\
\text { temp. }\end{array}$ & $\begin{array}{c}\text { bonding } \\
\text { test }\end{array}$ & $\begin{array}{l}\text { Substrate } \\
\text { dopant } \\
\times 10^{18 \text { cm }^{-3}}\end{array}$ & $\begin{array}{l}\text { Subst. } \\
\text { coating }\end{array}$ & $\begin{array}{c}\mathrm{H}_{2} \text { flow } \\
\text { rate } \\
\text { cc/min }\end{array}$ \\
\hline V-169 & 735 & $\Delta$ & $\mathrm{Te}$ & 3.5 & YES & 130 \\
M-99 & 765 & $\circ$ & $\mathrm{Te}$ & 3.5 & YES & 150 \\
M-130 & 780 & $\circ$ & $\mathrm{Se}$ & 7 & YES & 150 \\
M-125 & 790 & $\odot$ & $\mathrm{Se}$ & 7 & YES & 150 \\
M-129 & 800 & $\odot$ & $\mathrm{Se}$ & 7 & YES & 150 \\
\hline
\end{tabular}

๑: very good ०: good

$\Delta$ : moderate $\quad x:$ bad

The bonding tests were carried out on epitaxial wafers prepared at different substrate temperatures. Representative data are summariezed in Table 1. The data show that the bonding properties of the layer become good as the substrate temperature is raised within the temperature range above mentioned $\left(750^{\circ} \sim\right.$ $800^{\circ} \mathrm{C}$ ). The test of the epitaxial layer made at lower temperature showed that the top of the bonded junction reached the substrate through the epitaxial layer at the lower forward current, and in spite of the suitable layer thickness and concentration. This phenomenon may suggest that growth layer contains some defects.

\subsection{Effects of Hydrogen Flow Rate and $\begin{array}{lll}\mathrm{AsCl}_{3} & \mathrm{Temperature}\end{array}$}

Growth rate was also varied by the flow rate of hydrogen bubbled through the $\mathrm{AsCl}_{3}$ reservoir which was kept at $0^{\circ} \mathrm{C}\left(\mathrm{AsCl}_{3} / \mathrm{H}_{2}\right.$ mole ratio, $3.2 \times 10^{-3}$ ). A typical curve is shown in Fig. 6. It can be seen that the growth rate increases with increasing flow rate of the hydrogen containing $\mathrm{AsCl}_{3}$ up to about $100 \mathrm{cc} / \mathrm{min}$. but it remains nearly constant $(40 \sim 42 \mu / \mathrm{hr}$.) above 100 $\mathrm{cc} / \mathrm{min}$. Smooth surfaces were obtained in case of $60 \sim 150 \mathrm{cc} / \mathrm{min}$. In this case the substrate and $\mathrm{AsCl}_{3}$ temperature were kept constant at $780^{\circ}$ and $0^{\circ} \mathrm{C}$, respectively.

When the $\mathrm{AsCl}_{3}$ temperature was varied, the dependences of growth rate on the substrate and etching rate of the source on $\mathrm{As} \mathrm{Cl}_{3}$ temperature showed different behavior as shown in Fig. 7 . The growth rate increases with increasing temperature of $\mathrm{AsCl}_{3}$ and reaches a peak at about $-5^{\circ} \mathrm{C}\left(\mathrm{AsCl}_{3} / \mathrm{H}_{2}\right.$ mole ratio, $\left.2.2 \times 10^{-3}\right)$ and

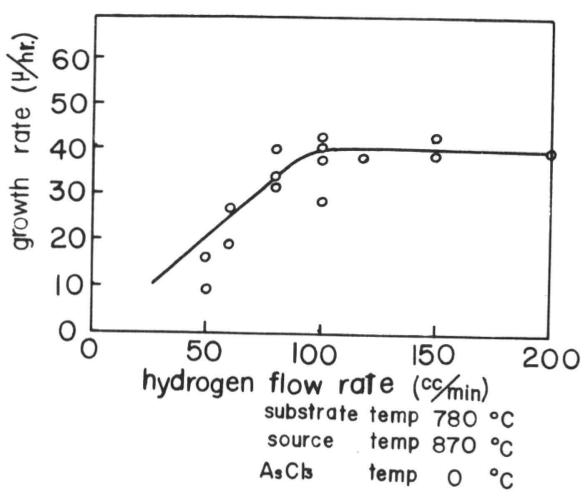

Fig. 6 Effects of hydrogen flow rate on growth rate at constant substrate temperature

gradually decreases. This decrease is due to the increase of competing etching reactions which in are induced by increases of unreacted $\mathrm{HCl}$ component from increased $\mathrm{AsCl}_{3}$ mole fraction. While the etching rate of source increases exponentially (the curve is parallel to the vapor pressure curve of $\mathrm{AsCl}_{3}$ ), the etching reaction is controlled by the vaporization heat of the $\mathrm{AsCl}_{3}$. Smooth surfaces were obtained at the $\mathrm{AsCl}_{3}$ temperature of $-8^{\circ} \sim 10^{\circ} \mathrm{C}\left(\mathrm{AsCl}_{3} / \mathrm{H}_{2}\right.$ mole

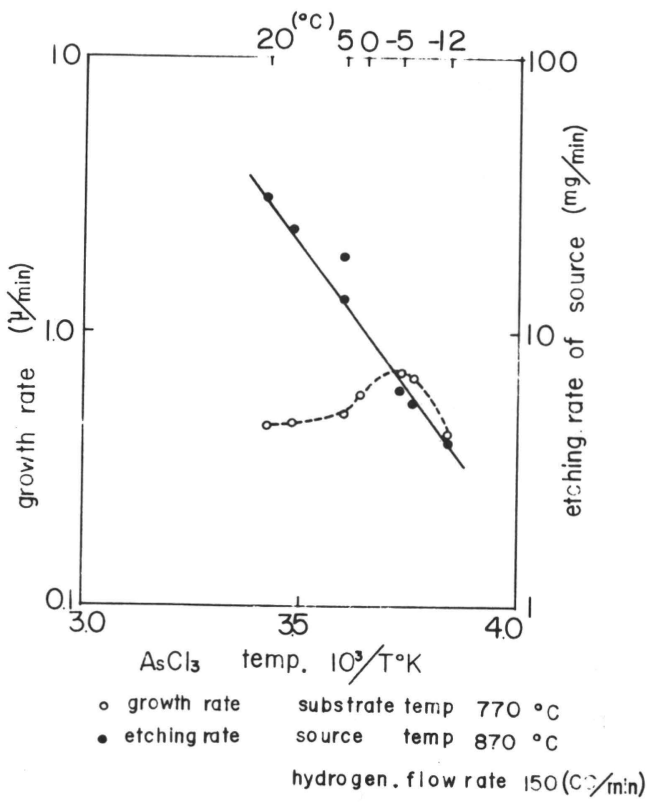

Fig. 7 Temperature dependence of $\mathrm{AsCl}_{3}$ on growth rate on substrate and etching rate of source 
Table 2 Representative data of the bonding tests for the epitaxial layers grown at different hydrogen flow rates and $\mathrm{AsCl}_{3}$ temperatures

\begin{tabular}{|c|c|c|c|c|c|c|}
\hline Sample No. & $\begin{array}{c}\mathrm{H}_{2} \text { flow rate } \\
\mathrm{cc} / \mathrm{min}\end{array}$ & $\mathrm{AsCl}_{3}$ temp. & Bond. test & $\begin{array}{r}\text { Substrat } \\
\times 10^{1} \\
\end{array}$ & $\begin{array}{l}\text { dopant } \\
\mathrm{cm}^{-3}\end{array}$ & Subst. coating \\
\hline M- 16 & 50 & $0^{\circ} \mathrm{C}$ & $\Delta$ & $\mathrm{Te}$ & 1 & NO \\
\hline M- 78 & 60 & 0 & $\Delta$ & $\mathrm{Te}$ & 3.5 & NO \\
\hline M- 82 & 60 & 0 & $x$ & $\mathrm{Te}$ & 3.5 & YES \\
\hline M- 21 & 80 & 0 & o & $\mathrm{Te}$ & 1 & NO \\
\hline M- 22 & 100 & 0 & (๑) & $\mathrm{Te}$ & 1 & NO \\
\hline M- 23 & 100 & 0 & $\circ$ & $\mathrm{Te}$ & 1 & NO \\
\hline M- 24 & 120 & 0 & 0 & $\mathrm{Te}$ & 1 & NO \\
\hline M- 25 & 150 & 0 & ๑ & $\mathrm{Te}$ & 1 & NO \\
\hline M-139 & 150 & -4 & $x$ & $\mathrm{Te}$ & 3.5 & YES \\
\hline M-177 & 150 & +11 & $\hat{x}$ & $\mathrm{Te}$ & 3.5 & YES \\
\hline M-179 & 150 & +20 & $\hat{x}$ & $\mathrm{Te}$ & 3.5 & YES \\
\hline
\end{tabular}

(๑) : very good

०: good
$\Delta$ : moderate

$\mathrm{x}$ : bad ratio, $1.8 \sim 6.1 \times 10^{-3}$ ), but the humps were observed above $10^{\circ} \mathrm{C}$, while irregular surfaces were observed below $-8^{\circ} \mathrm{C}$.

The bonding tests were carried out on the epitaxial layers and the results are summarized in Table 2. The results show that electrical properties of the epitaxial layer deposited under the condition of the hydrogen flow rate above 100 $\mathrm{cc} / \mathrm{min}$. is better than those of below $100 \mathrm{cc} / \mathrm{min}$. In case of low flow rate, values of the PCB voltage of growth surface is scattered. It can be seen that the layers made under the $\mathrm{AsCl}_{3}$ atmosphere at $0^{\circ} \mathrm{C}$ are favorable, although experiments on this phase is incomplete.

\section{Effects of Impurities}

\subsection{Impurities in Source Crystals}

An impurity concentration in the growth layer is controlled differently by the kind and concentration of impurity in the source crystal. Transfer ratios for donor impurities ${ }^{7)}$ investigated here are summarized in Table 3 . The epitaxial layers with needed impurity concentrations are grown by the choice of source crystals with a certain impurity concentration referred to above values.

The bonding tests were carried out on the epitaxial layers doped to $2 \sim 3 \times 10^{17} \mathrm{~cm}^{-3}$ with $\mathrm{Te}, \mathrm{S}$ and $\mathrm{Sn}$, respectively. Representative data are shown in Table 4 . The tests show that the epitaxial layer doped with $\mathrm{Sn}$ is the most efficient and the layer doped with $\mathrm{S}$ is subse-
Table 3. Transfer ratio for various donor impurities

Group IV

\begin{tabular}{c|c|c}
\hline Impurity & Transfer ratio & Elect. negativity \\
\hline $\mathrm{Si}$ & $0.03-0.07$ & 1.8 \\
$\mathrm{Ge}$ & $\simeq 1$ & 1.8 \\
$\mathrm{Sn}$ & $0.6-0.7$ & 1.7 \\
\hline
\end{tabular}

Group VI

\begin{tabular}{l|r|r}
\hline \hline $\mathrm{S}$ & $0.5-0.6$ & 2.5 \\
$\mathrm{Se}$ & $\simeq 1$ & 2.4 \\
$\mathrm{Te}$ & $\gtrsim 1$ & 2.1 \\
\hline
\end{tabular}

quently good but the layer doped with $\mathrm{Te}$ is unsuitable. This result is not clarified but there is a difference in the electron mobility of the layer deposited on the semiinsulating substrate between $\mathrm{S}$ or $\mathrm{Sn}$ doped and Te doped samples as shown in Table 5. It can be seen that $\mu_{\mathrm{s}}>\mu_{\mathrm{Sn}}>$ $\mu_{\mathrm{Te}}$ in the impurity concentration of $10^{17} \mathrm{~cm}^{-3}$. The reason why the S-doped layer is subsequently good is due to a little imhomogeneous distribution of impurities on the layer measured by the PCB method. In the case of Te-doped layer lattice defects such as precipitation of $\mathrm{Ga}_{2} \mathrm{Te}_{3}{ }^{8)}$ which make worse electrical properties of the layer should be considered.

\subsection{Effects of Impurities in Substrates}

It is one of the important factors for the devices that the substrate is below $0.9 \times 10^{-3}$ 
Table 4 Representative data of the bonding tests for the epitaxial layers doped with $\mathrm{S}, \mathrm{Sn}$, and Te

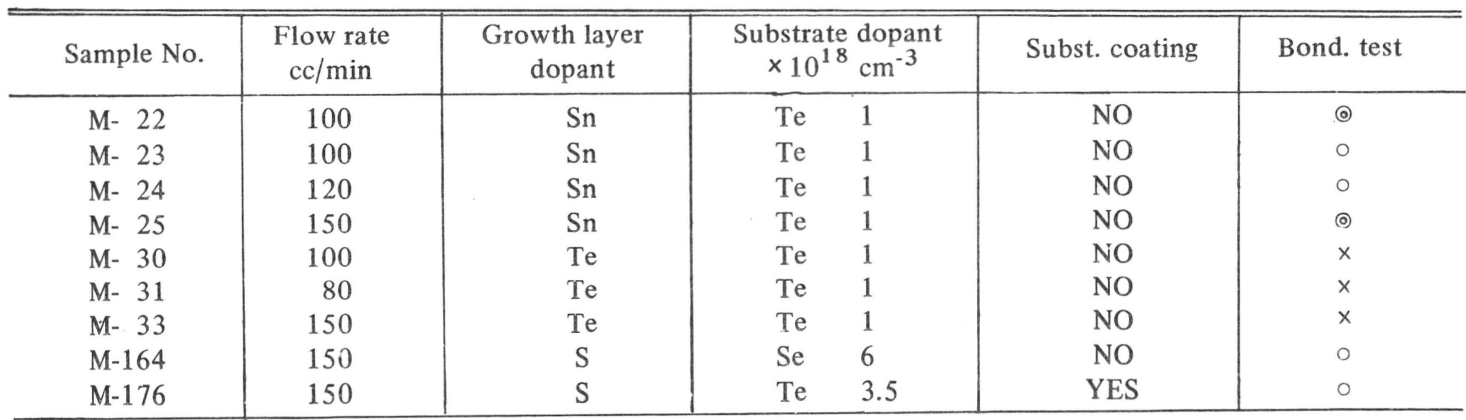

๑: very good

○: good

$x$ : bad

Table 5 Electron mobility data for S, Sn, and Te doped layers of epitaxial GaAs

\begin{tabular}{c|c|c}
\hline \hline Dopant & $\begin{array}{c}\text { Carrier conc. } \\
\mathrm{cm}^{-3}\end{array}$ & $\begin{array}{c}\text { Electron mobility } \\
\mathrm{cm}^{2} \mathrm{v}^{-1} \mathrm{sec}^{-1}\end{array}$ \\
\hline $\mathrm{Te}$ & $2-3 \times 10^{17}$ & $1300-2600$ \\
$\mathrm{Sn}$ & $2-3 \times 10^{17}$ & $2800-3500$ \\
$\mathrm{~S}$ & $2-5 \times 10^{17}$ & $3000-3700$ \\
\hline
\end{tabular}

$\Omega \mathrm{cm}$ of resistivity, in other words above $3.5 \times$ $10^{18} \mathrm{~cm}^{-3}$ in donor concentration. Single crystals satisfactory to the specification were difficult to get from melt grown ingots except cases of Te-or Se-doped crystals. In the Te- or Se-doped crystals favorable slices as the substrates were difficult to get without any troubles. In the epitaxial layer deposited on heavily doped substrate, it is known that the impurity profile near the interface becomes graded because of incorporation of impurity from substrate to growth layer ${ }^{9}$ ). These effects were remarkable in the use of Te- or Se-doped substrates and were less remarkable in $\mathrm{S}$ or $\mathrm{Sn}$ doped ones but not sufficent for device fabrication as far as our research extended.

The bonding tests were carried out on the epitaxial layers doped to $2 \sim 3 \times 10^{17} \mathrm{~cm}^{-3}$ with $\mathrm{Sn}$ onto the substrate doped to $3.5 \sim 7 \times 10^{18}$ $\mathrm{cm}^{-3}$ with $\mathrm{Se}$ or Te. The results are not good as shown in Table 6. This may be attributed to graded impurity profile in the layer. It was made clear from measuring of the impurity profile that a donor concentration of $10^{17} \mathrm{~cm}^{-3}$ is reached $\sim$ $1.0 \mu$ for the above layer. This main cause is
Table 6 Results of the bonding tests for the epitaxial layers deposited on coated and un coated substrates

\begin{tabular}{c|c|c|c|c}
\hline $\begin{array}{c}\text { Sample } \\
\text { No. }\end{array}$ & $\begin{array}{c}\text { Substrate } \\
\text { dopant } \\
\times 10^{18} \mathrm{~cm}^{-3}\end{array}$ & $\begin{array}{c}\mathrm{H}_{2} \text { flow rate } \\
\mathrm{cc} / \mathrm{min}\end{array}$ & Bond. test \\
\hline \multicolumn{4}{c}{ NO coating treatment } \\
\hline M- 85 & Se & 6 & 150 & $\times$ \\
M- 79 & Te & 3.5 & 130 & $\circ$ \\
V-148 & Te & 7 & 90 & $\times$ \\
M-112 & S & 4 & 150 & $\circ$ \\
M- 75 & Sn & 10 & 150 & $\odot$ \\
\hline \multicolumn{5}{|c}{ coating treatment } \\
\hline M-115 & Se & 6 & 150 & $\circ$ \\
M-111 & Te & 3.5 & 150 & $\odot$ \\
M- 99 & Te & 7 & 150 & $\circ$ \\
\hline
\end{tabular}

$\odot$ : very good $\circ$ : good $\quad \mathrm{x}$ : bad

owing to an autodoping effect of substrate during growth as described previously.

The substrate coating method was attempted to prevent autodoping from substrate; the opposite side and fringes of the substrate were more fully covered by a low donor concentration layer than that of the deposition layer beforehand. Resultant layers showed recovery of the properties in the bonding tests and the donor concentration of $10^{17} \mathrm{~cm}^{-3}$ was reached $\sim 0.3 \mu$. in the impurity profile.

When the epitaxial grown substrates doped to $5 \times 10^{18} \mathrm{~cm}^{-3}$ with $\mathrm{Sn}$ were used ${ }^{10}$ ) the bonding tests showed very good properties and donor concentration of $10^{17} \mathrm{~cm}^{-3}$ was reached $\sim 0.3 \mu$ in the impurity profile as shown in Fig. 8 . 
8.

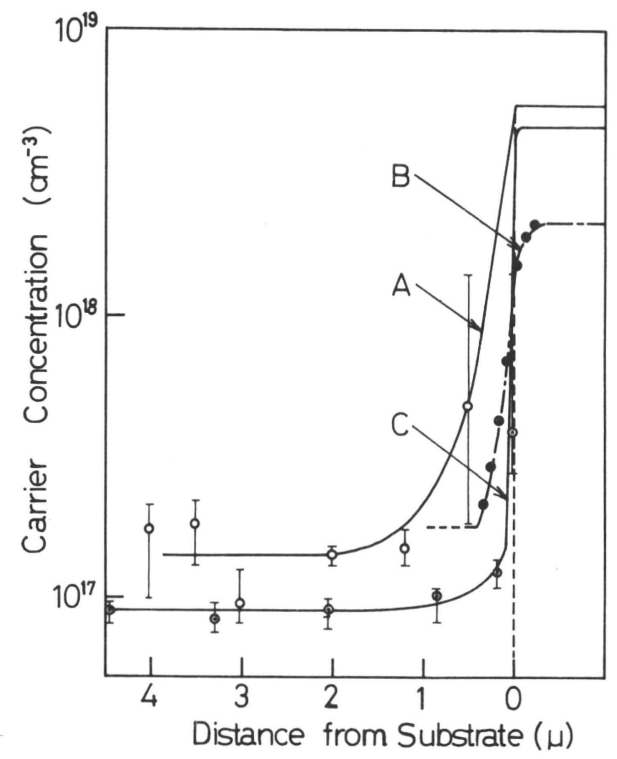

A. Substrate Se doped $6.0 \times 10^{18} \mathrm{~cm}^{-3}$ uncoated

B. Substrate Sn doped $1.8 \times 10^{18} \mathrm{~cm}^{-3}$ uncoated

C. Substrate Te doped $3.5 \times 10^{18} \mathrm{~cm}^{-3}$ coated

Fig. 8 Impurity profile for the epitaxial layers

\section{Conclusions}

The bonding tests are very effective methods to know the quality of epitaxial layers, especially in choice of epitaxial wafers for bonded type devices. This method may give all-round examination of so-called "crystallinity" in thin films.

To get good crystalline deposition layers of epitaxial GaAs the following articles are presented;

1. Substrate temperature is good as high as possible in the region where smooth growing surface is obtainable.
2. Hydrogen flow rate is favorable in the range of the remaining constant growth rate because the growth rate is insensible to variation of the flow rate.

3. Sn- or S-doped layers are good in the electrical properties for bonded diodes.

4. When highly doped substrates with $\mathrm{Te}$ or $\mathrm{Se}$ are used, the substrate coating method with heigh purity $\mathrm{GaAs}$ is effective to prevent the substrate from impurity in corporation in the growth layers.

Acknowledgement: This work has been carried out in " co-operation with The Electrical Communication Laboratory, Nippon Telegraph and Telephone Public Corporation, and the authors wish to express their sincere appreciation to Drs. T. Imai, Y. Ishii, Y. Furukawa, M. Yamaguchi and other members of the millimeter wave diodes research group for many stimulating discussions and encouragements. Thanks are extended to Drs. T. Seki, T. Sekiguchi, T. Taniguchi, H. Kusumoto, M. Kamimura, Y. Sugita and M. Migitaka of Hitachi Central Research Laboratory.

\section{References:}

1) C. A. Burrus, Proc. IEEE 51, 1777 (1963).

2) D. Brady, S. Knight, et al., Proc. IEEE 54, 1497 (1966).

3) D. Effer, J. Electrochem. Soc. 112, 1020 (1965).

4) R. L. Newman, N. Goldsmith, J. Electrochem. Soc. 108, 1127 (1961).

5) Y. Ishii, M. Fujimoto et al., Millimeter Wave Symposium of The Electrical Communication Laboratory, Nippon Telegraph and Telephone Public Corporation, 9th Oct., 1968.

6) Y. Ishii, Y. Sato et al., Hitachi Hyoron 50, 59 (1968).

7) T. Okada, F. Hasegawa et al., The 3rd Symposium on Semiconductor Materials, 6th Dec., 1966 (Electrochem. Soc. Japan).

8) H. Kressel et al., J. Appl. Phys. 40, 3587 (1969).

9) K. L. Lawley, J. Electrochem. Soc. 113, 240 (1966).

10) H. Sato, S. Iida, J. Appl. Phys. 9, 156 (1970). 